\title{
Sketching with Students: An Arts-informed Qualitative Analysis of First- year Engineering Students
}

\section{Desen Sevi Ozkan, Virginia Tech}

Desen is a PhD student in Engineering Education at Virginia Tech. Prior to studying at VT, she worked in the Biosystems engineering department at the University of Tennessee, Knoxville as a research assistant focusing on wastewater engineering and water reclamation. Desen holds a B.S. in Chemical Engineering from Tufts University and is on track to completing her M.S at Virginia Tech. She was born in Arlington, Texas, then moved to Istanbul, Turkey, and then to Boston to pursue her B.S. She speaks Turkish fluently. Her $\mathrm{PhD}$ focus is on creativity and design in engineering education. When not studying or teaching, Desen is riding her bikes up and especially down the mountains of Southwest Virginia.

\section{Dr. Cherie D. Edwards, Virginia Tech}

Dr. Cherie D. Edwards is a Postdoctoral Associate in Engineering Education at Virginia Tech. She earned her Ph.D. in Educational Research and Evaluation from Virginia Tech. Her research and scholarship are focused on exploring the implementation of mixed methods, qualitative, and arts-informed research designs in studies examining issues of social justice and educational equity. Currently, she is on a research team examining the impacts of an out-of-school STEM summer program for racially underrepresented youth.

\section{Dr. Sreyoshi Bhaduri, Virginia Tech}

Sreyoshi Bhaduri recently graduated with a Ph.D.in Engineering Education from Virginia Tech. She has an M.S. in Mechanical Engineering, and an M.A. in Data Analytics and Applied Statistics (DAAS) both from Virginia Tech. Sreyoshi's research interests include working on innovative research designs for analyzing varied datasets and presenting the results of these analyses to various stakeholders through meaningful and easily interpretable visualizations. Sreyoshi was recognized during her time at Virginia Tech as a Diversity Scholar, was a part of the Global Perspectives Program (GPP-2013), served as a Fellow of the Academy for Graduate Teaching Excellence (VT-GrATE), and was inducted into the prestigious Bouchet Graduate Honor Society.

\section{Dr. Diana Bairaktarova, Virginia Tech}

Diana Bairaktarova is an Assistant Professor in the Department of Engineering Education at Virginia Tech and the Director of the Abilities, Creativity and Ethics in Design [ACE(D)]Lab. Bairaktarova's ongoing research interest spans from engineering to psychology to learning sciences, as she uncovers how individual performance and professional decisions are influenced by aptitudes and abilities, interest, and manipulation of physical and virtual objects. 


\title{
Sketching with Students:
}

An Arts-Informed Qualitative Analysis of First-Year Engineering Students

\begin{abstract}
This Complete Research paper explored the identities of first-year engineering students through qualitative inquiry using an arts-based approach. In this study, first-year engineering students from a remedial spatial visualization class were tasked with sketching themselves. We used the sketches to uncover a holistic representation of how the students choose to identify themselves. To analyze these drawings, we used a theoretical coding approach employing Gee's four categories of identity (nature-identity, institution-identity, discourse-identity, and affinityidentity). We coded all relevant features of the sketches to the appropriate category. Second-tier codes were then developed based on the specific characteristics of each of Gee's four categories of identity. Participant reflection statements were coded using the same approach. Once participant drawings and reflection statements were coded, we examined the codes and categories to identify emergent themes.
\end{abstract}

Keywords: arts-based research, sketching, first-year engineering, spatial visualization, identity, qualitative methods, exploratory

\section{Introduction}

Sketching as a practice can be applied in various ways. The practice itself changes based on its intended purpose or application. For this paper, we borrow the definition for the term sketching from Song and Agogino, who describe it "broadly to include all early-stage forms of graphical representations of design, including rough freehand drawings or computer-rendered drawings and conceptual solid models" [1]. In engineering, sketches have a variety of uses, in that they can be used for brainstorming ideas or for social and communicative practices, which differs slightly from that in other fields. Sketching in engineering is used for field-related practices as well as for exploratory and ideation purposes. Each of these purposes offers a critical piece of learning that may need to be used in conjunction with one another. With the versatility of sketching practices, there are inevitable challenges when determining the appropriate times and contexts to employ these methods as well as the distinctions in defining the term. Additionally, for students who do not consider themselves artistic, there can be more hesitation associated with using sketching as a way to think and communicate due to the fear of judgment that can be associated with expressing oneself. Therefore, when we begin to bring sketching back into the engineering classroom, we also need to help our students overcome this mental obstacle and become comfortable using sketching as a tool.

In engineering education, we limit the amount of sketching, specifically free-hand drawing expected of students. This form of drawing has become an act of vulnerability, ridding its perceived usefulness as an engineering tool. In the past, engineers relied heavily on their ability to draw for three reasons - nonverbal thinking, prescriptive sketching, and communication [2]. Nonverbal thinking spans the rough and unrealized ideas that are explored on paper, which is what we will be using in this study. Prescriptive sketching constitutes more of the problemsolving in engineering, in which these sketches help flush out ideas and ensure that they are 
technically viable. Lastly, communication, or the talking sketch speaks to the ability sketches have in communicating aspects of the design [2]. More and more, students are being taught to rely on computers to design their processes and products, which reduces the need to sketch throughout the stages which inevitably reduces their need to think throughout the stages.

Engineering design is a complex process that rarely follows a linear process. Drawing eases the process by offering a medium by which engineers can "try out new ideas, compare alternatives, ... and capture fleeting ideas on paper" [2]. However, the ease at which sketching can be used in this manner necessitates that the engineering student goes through the curriculum having had exposure to sketching. With the advent of computer-aided design tools, students are losing comfort with freehand sketching, leaving little room to document the momentary ideas that often occur in design. Architects and artists, two other fields which draw heavily from design education, use drawing and sketching in each stage of the design process [2]. By using sketching as a tool throughout the curriculum, these fields overcome issues of vulnerability and talent by using sketches to understand what students are drawing, rather than if students can draw. In the transition from sketching by hand to computer-aided design tools, undergraduate engineering students are being stripped of many of the implicit benefits that come with the use of sketching as an engineering tool. In engineering education, there is a growing need to reintroduce freehand sketching to students through less threatening means such as using a sketch to show who they are.

The study took place in a first-year spatial visualization class taught to engineering students. To get student more comfortable using free-hand sketching in their coursework, the instructor used low stake sketching prompts throughout the semester. The sketches this study takes an interest in are those that are free-hand and exploratory. Of all the sketches collected, this research study sought to investigate the initial sketches, which asked students to sketch who they are, as a form of self-expressed identity. We believe that exploring these student sketches will yield powerful insight into first-year engineering student identities and that these identities will develop further forming professional identities as the students continue their interactions and participation in the engineering sketching activities. In fact, Tonso presents professional identity as a negotiation between the social expectations related to a professional role and the needs, wants, and aptitude of individuals engaging in that role [3]. Thus, student identities towards the beginning of the first-year program may provide valuable insight into their professional identities in engineering. Tonso also recognizes that professional identity could relate to important professional competencies [3]. Thus, students engaged in the course are likely to develop their professional competencies, as they navigate through the problem-solving.

Engineering student identity, as a topic, has been studied extensively. Thus, identity as a term has a variety of meanings and connotations that can confound the construct. Identities can be perceived differently by different people, and aspects of it are subject to change. Gee's use of identity begins with his assertion that identity is "being recognized as a certain kind of person" [4]. Development of engineering student identities is crucial for engineering classrooms. The Committee on the Guide to Recruiting and Advancing Women Scientists and Engineers in Academia presented a report which states that the first-year programs are critical for retention of minorities in engineering classrooms and that building strong engineering identity through the first-year courses can help facilitate inclusion of minorities [5]. Pedagogically too, inter- 
disciplinary-design and problem-based learning environments such as the one afforded in this remedial spatial visualization course have been shown to facilitate identity development and identity retention amongst individuals in the engineering classrooms [3,6]. Recognizing the relevance and significance of identity formation and development in engineering classrooms, the research question driving this exploratory study is:

RQ1 - How do first-year engineering students in a remedial engineering visualization course convey their identities through in-class identity maps?

Thus, students come into higher education with an assortment of different things they identify with or as. Through their dress, their associations, their manner of speech, even their intended major, we make assumptions to make sense of 'who they are.' With this study, we have provided a different medium in which the students can represent themselves. To frame their sketches, we have employed Gee's identity framework [4]. In the following sections, we present a more detailed discussion of visual thinking and the lens through which we analyzed identity in the course detailed.

\section{Background}

Seeing is thinking. We live in a very visual-centric society. Visual thinking is not housed only in the 'artist's mind' but in the engineer's as well [7]. When we see, imagine, and draw things, we are thinking visually. These three types of visual thinking cannot exist in silos, for with increased flexibility, they interact, which denotes an expert designer [7]. Expert engineers almost always sketch in their work, even with the adoption of computer software [8]. A study on expert engineers shows that sketching on paper is used by $90 \%$ of interviewed German engineers before and during their CAD work [8]. Engineering design is highly dependent on collaborations among teams for successful problem-solving. Sketching is a crucial aspect of brainstorming, communication, and overall problem-solving in design thinking and consequently, design engineering [9]. By enhancing student confidence in sketching, we are indirectly developing their visual thinking abilities, which are paramount in solving problems without a clear beginning [7, 8]. Different types of sketching can act as a form of framing and re-framing a problem and offer critical skillsets for engineers. In other design disciplines, problem definition begins with a sketching stage that then informs the entire process of design.

In The Craftsman, Sennett draws attention to the use of Computer Aided Design (CAD) in architectural teaching [11]. Sketching ensures that the designer becomes familiar with a site such that it is "ingrained in their mind" [11]. There exists a circular process by which the designer draws the site, goes to the site, revisits the drawing, goes back to the site and so forth; this iterative process of sketching highlights issues that can be difficult to find initially $[1,9]$. Moreover, with computer software, the circularity embedded in drawing by hand is no longer necessary, for each action on CAD has far fewer consequences, which results in less consideration when carrying them out [11].

Sketching by hand and CAD also differ in how students perceive them. Sketching is seen more as an innate ability by the more 'artistic' students and CAD is better understood as a program that must be learned. Consequently, the built-in preconception of CAD as a skill to be improved 
upon diverts students to use it as their first step in design. Scrubbing students of their ill conceptions of sketching by reframing it as a tool will help improve their design processes and dispel notions that the sketches are the product. One aspect of sketching that is often overlooked is its ability to reframe 'half-baked thoughts' by representing them in a different light [12]. These 'half-baked ideas' can be in the context of design ideas or even in one's identity.

With this study, we have tasked students to represent themselves through a sketch as a way to have them explore and convey aspects of themselves that they may not immediately think of if they were to communicate themselves with a different medium such as speaking or writing.

\section{Theoretical Framework}

We have explained the relevance and significance of fostering identity development in formative engineering courses. In the context of education, identity analysis has become an important tool [4]. Gee's framework views identity through four perspectives, nature-identity, discourseidentity, institution-identity, and affinity-identity. Each of these lenses is ways to view identity. These four views are analytic tools that overlap and interact with one another to better represent the facets of an individual's identity.

The first perspective from Gee's framework is a nature-identity, which is a state that one is in. For instance, being born into a certain identity, rather than doing anything to garner the identity. The example of this perspective that Gee provides is being an identical twin. Nature-identity is "developed from the forces in nature"; society cannot have any effect on one's nature-identity [4]. For students, this could be the heritage in which they are born into, or their left or righthandedness.

Next is an institution-identity, which is a "position authorized by authorities within institutions" [4]. Being a student at a university is an example of this aspect of identity. Another example would be a leadership position in a team or group, for instance, student body president. The authority of the institution employs laws, rules, traditions, or principles to "author" this identity of the student. Institutional identity can be strengthened by discourse identity which speaks to how one is recognized.

The discourse-identity perspective takes into account individual traits of the person, not looking at qualities that people are born with. This trait is "recognized in the dialogue or discourse of "rational' individuals" [4]. Rational in this context is defined as individuals giving reasons for identifying the particular trait, such as humor. The reasons are not from tradition, laws, or other institutional authorities (for this would make this a type of institutional identity discussed above). This facet of identity is sustained by the regularity in which specific types of discourse, dialogue, and interactions take place to sustain the overarching discourse identity. For instance, if a someone is constantly making jokes or presenting themselves as the 'funny person,' then they are recognized as such and sustain the identity. Discourse identity is a form of recognition, which can result in a variety of discourse identities being applied to the same individual due to the differences in potential recognition across 'rational' individuals [4]. 
The final perspective is affinity-identity, which is "experiences shared in the practice of affinity groups" [4]. This perspective is made up of the sets of practices that revolve around a common endeavor. As an example, an affinity identity can show that an individual has the identity of a cyclist. This identity is formed through the shared the experience of riding bicycles with others, talking about cycling on internet forums, or in person, complimenting other cyclists on their bikes among other practices. The members of an affinity group can be spread across different regions; the affinity group is based on individuals" "participation in specific practices" [4].

Each of these views of identity is interrelated and support one another. For instance, as a student at a university, there is institutional-identity imposed by the university as well as affinity-identity if the student takes part in the student activities that are university-related, for instance, sporting events. Discourse-identity becomes a factor in the interactions and dialogue that occur among students about such events.

\section{Methods}

The students whose sketches were collected for this study are from a first-year remedial course on introduction to spatial visualization. Enrolling in the course is strongly encouraged for students who score below an eighteen out of thirty on the Purdue Spatial Visualization Test: Visualization of Rotations (PSVT:R) [13]. The remediation aspect of the course makes it even more important to expunge misconceptions students have with their sketching abilities. Throughout the semester, the professor's instruction used creative ways of learning that targeted developing and enhancing students' spatial reasoning. Students practiced freehand sketching inside and outside the classroom, learned Computer Aided Design (CAD), designed for additive manufacture, and manipulated 3D printed objects. The instructor consistently encouraged the students to freehand sketch objects, to enhance their ability to see the details in the physical environment. The instructor employed various exercises throughout the semester to instill confidence in the students' freehand sketching abilities. Altering students' mindsets on what can be learned and improved is a crucial element to their development in becoming confident lifelong learners and was an implicit focus in the course.

This study was framed as an arts-informed research study purposed with examining the visual representations of first-year engineering undergraduate students in a remedial spatial visualization course. We conceptualize arts-informed research as a tool of an arts-based method that enables data collection, analysis, interpretation, or social representation [14]. Furthermore, arts-informed methods encourage free and authentic expressions that do not limit participant expression through verbal communication [15].

\section{Data Collection}

The spatial visualization class the sketches were collected from consisted of 169 students, of which 92 were male, and 77 were female. The percentage of female students was much higher than that of the average engineering class at almost $46 \%$ female students. The U.S. average of women who graduate with undergraduate engineering degrees is $18-20 \%$ [16]. As to how this may have affected the class dynamic was left unobserved, for the students submitted the sketches in the first week of their first semester of class. Additionally, effects of the remediation stigma were also left unexplored and are future avenues of research to pursue. The sketches were 
collected in the form of a 5-point star exercise shown in Figure 1. The exploratory study conducted by Ozkan and Bairaktarova (2017) investigates the themes that emerged in the five points [17]. The questions were designed to allow the students to present themselves with an open-ended and reflexive exercise.

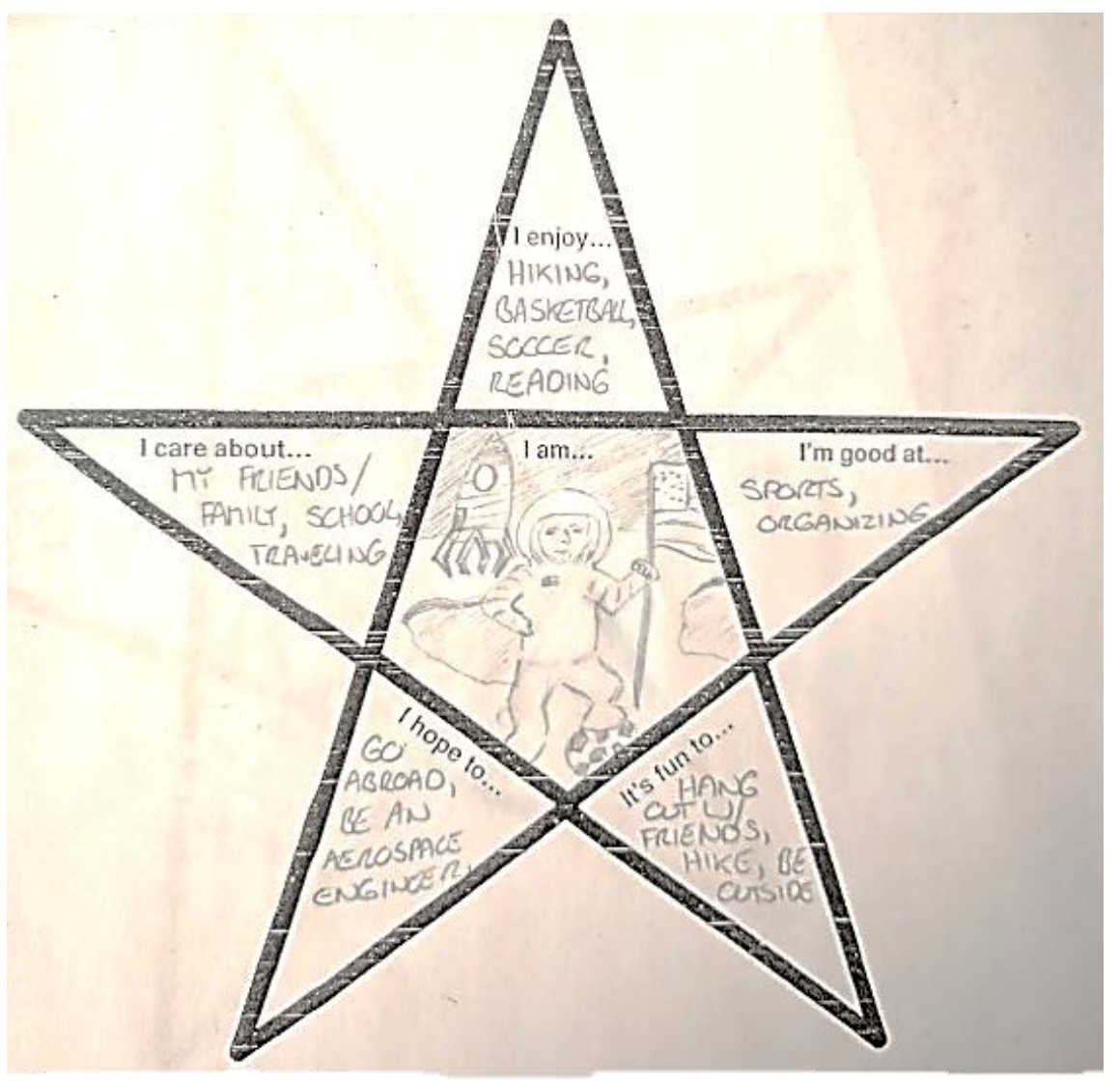

Figure 1. 5-Point Star

\section{Methods of Analysis}

As Anfara, Brown, and Mangione state, initial coding is often used to identify descriptive segments of data while simultaneously highlighting nuanced experiences of participants [18]. While this approach to qualitative analysis is commonly applied to words and text, it can illuminate descriptive trends in visual data as well. In this study, initial coding was the first step of the analysis. Through initial coding, we were able to descriptively summarize the key symbols from each participant's drawings. Our sample size for this study was 48 student drawings. Figure 2 below details the steps followed in our analysis. 

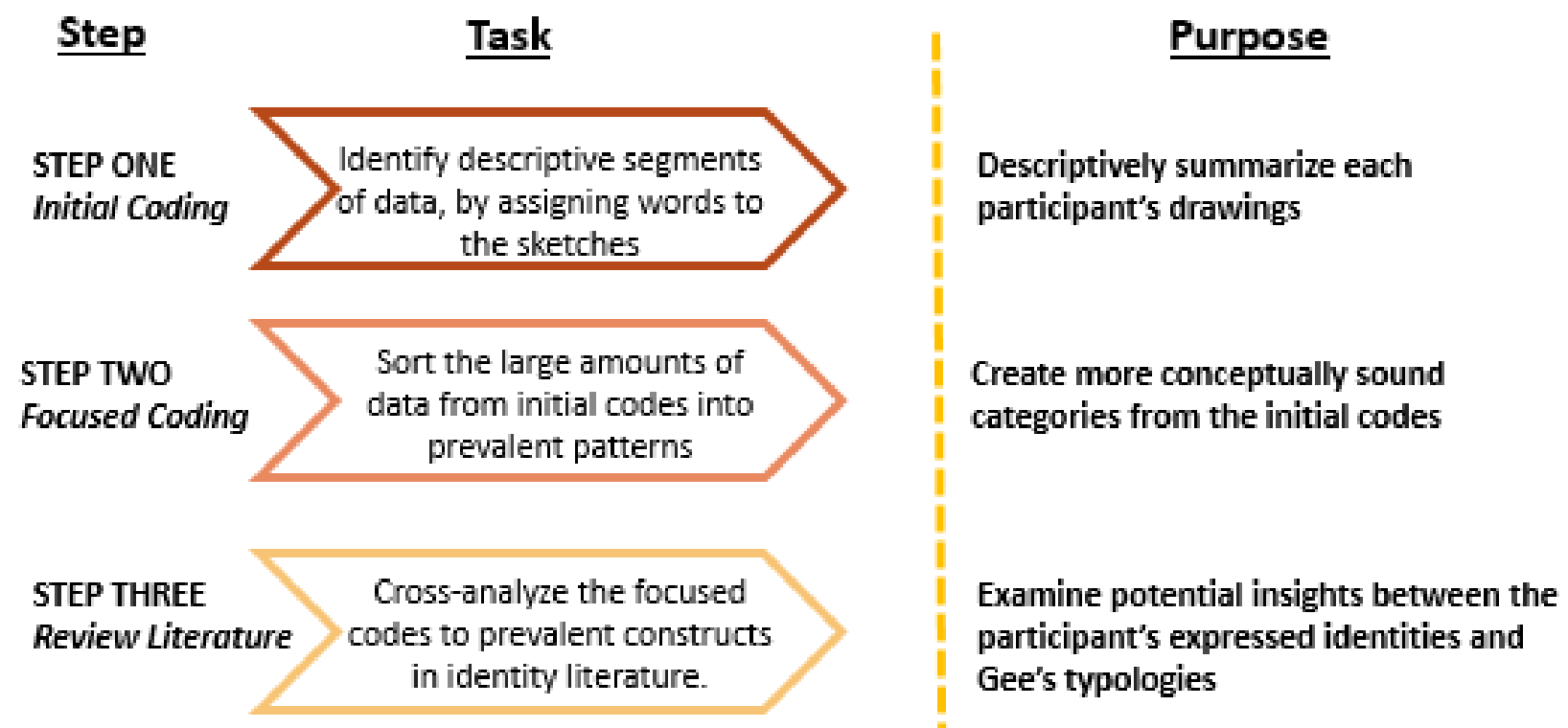

Figure 2. Steps of Data Analysis

The next step of analysis was focused codes. Focus coding involves sorting large amounts of data based upon prevalent patterns that emerge from the initial codes [19]. Through focused coding, descriptive codes identified during the initial coding process are placed in more conceptual sound categories [20]. The focused codes developed during the second round of coding were used to cross-analyze prevalent constructs found in the engineering identity literature. The purpose of employing this approach was to examine the way in which participants in study communicated aspects of identity was aligned with the constructs in engineering identity literature. Essentially, this approach was employed to examine the potential insight into the nuances between participants expressed identities and the theorized constructs of identity in Gee's identity typologies [4].

\section{Findings}

Through initial coding, 75 descriptive codes were identified from a total of 48 participant drawings. After controlling for repetitive codes, there were a total of $\mathbf{3 7}$ initial codes identified. These 37 codes were organized into three conceptual categories. Table 1 summarizes the final initial codes and how they were organized into more conceptual sound focused codes. The findings of this arts-informed analysis suggest that participants communicated their identities through depictions of hobbies and value-symbolic images. In addition, some participants engaged in self-reflective drawings to communicate their identities. 
Table 1. Identity Star Coding Summary

\begin{tabular}{|c|c|c|c|}
\hline Categories & Valued Hobbies & Reflective Self Depictions & Value-Symbolic Images \\
\hline Definitions & $\begin{array}{l}\text { Participants depict images } \\
\text { of hobbies to illustrate their } \\
\text { values. This may include } \\
\text { items used for hobbies or } \\
\text { images of activities in } \\
\text { progress. }\end{array}$ & $\begin{array}{l}\text { Participants depict images } \\
\text { of themselves. The images } \\
\text { include stick figures or self- } \\
\text { portraits. }\end{array}$ & $\begin{array}{l}\text { Participants included } \\
\text { symbolic images to } \\
\text { communicate specific } \\
\text { values. Participant used } \\
\text { these images to convert } \\
\text { professions, goals, values, } \\
\text { and or interest. }\end{array}$ \\
\hline \multirow{18}{*}{ Initial Codes } & Bullwhip & \multirow{4}{*}{ Neutral Stick Man } & \multirow{2}{*}{ United States Flag } \\
\hline & Tennis Shoes & & \\
\hline & Trials & & House \\
\hline & Soccer ball & & Institution Mascot \\
\hline & Woman (Smiling) & \multirow{3}{*}{ Calculating Equations } & \\
\hline & Swimming & & \\
\hline & $\begin{array}{l}\text { Sports (Multiple Items } \\
\text { Represented) }\end{array}$ & & \multirow[t]{2}{*}{ Abstract drawing } \\
\hline & Guitar & \multirow{4}{*}{ Happy Face } & \\
\hline & Running & & Glasses \\
\hline & Music & & Star \\
\hline & Books & & Texas \\
\hline & Basketball & \multirow{7}{*}{$\begin{array}{l}\text { Woman (Touching Eye) w/ } \\
\text { Cross }\end{array}$} & Tool Box \\
\hline & Lacrosse & & Institution Name \\
\hline & Playing Tennis & & Wrench \\
\hline & Cycling & & Bar Graph (Improving) \\
\hline & Detailed Stick Figure & & \\
\hline & Math & & \multirow[t]{2}{*}{ Mathematical Symbols } \\
\hline & Sleeping & & \\
\hline
\end{tabular}

\section{Valued Hobbies}

The category valued hobbies held images of hobbies participants used to communicate their identities. While the true significance of these drawings cannot be illustrated through the pictures alone, the inclusion of these hobbies suggests a high magnitude of value as it pertains to the participants' identities. This category included images that clearly represented pastime activities (e.g., books, ballet shoes, soccer balls). The inclusion of pastime interests to communicate aspects of identity follows a similar trend from previous arts-informed studies examining aspects of identity as participants commonly depict their

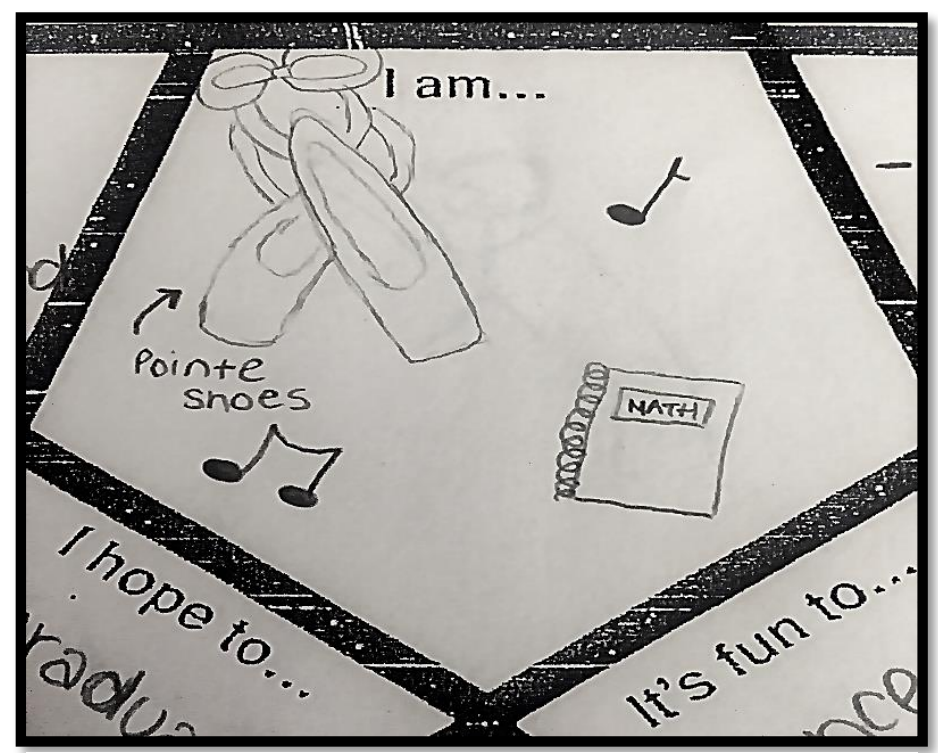

Figure 3. Value Hobby Drawing hobbies as important components of who they perceive themselves to be [15]. Figure 3 illustrates an example of a value hobby drawing. 


\section{Reflective Self Depictions}

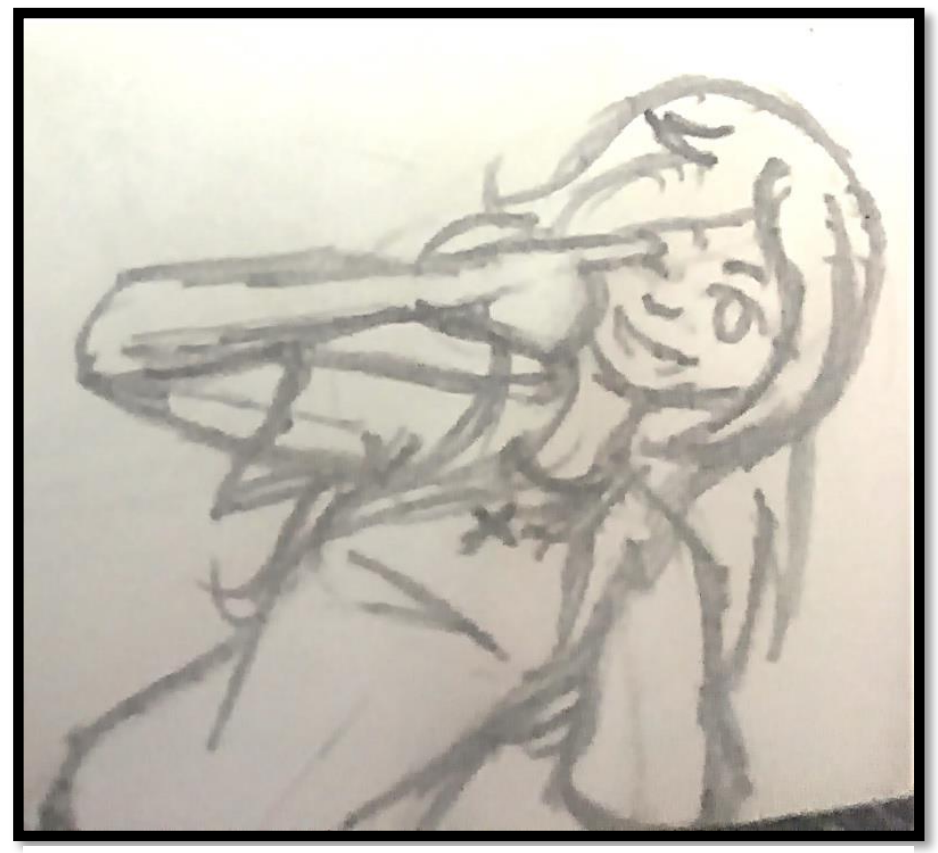

Figure 4. Reflective Self-Depiction Drawing
Reflective self-depictions were another common manner by which participants communicated their identities. These were most commonly depicted with drawings of participants' faces and stick figures. Although this was not the most prevalent category, it illuminates the presence of self-reflection in the student drawings. As articulated by Grace and Wells [20], arts-based methods increase participants' capacity to address issues related to self as well as to the world around them. These self-depictions may exemplify this progression, especially as it relates to students' professional and discipline-oriented identities. Participants drawing self-images may suggest that they have yet to develop professional identities. Alternatively, with a majority of these images depicting participants

with smiles on their faces, these drawings may indicate participants' desire to communicate their state of emotion in lieu of overt connections to roles, disciplines and/or activities. Figure 4 is an example of a reflective self-depiction drawing.

\section{Value Symbolic Images}

While most drawings can be identified as holding some symbolic value, our findings suggest that specificity in identity drawings often vary. The value symbolic image demonstrates a category with more ambiguous identity drawings. As such, we conceptualize symbolic images as depictions that may not directly link to hobbies or self-depictions, but still, hold some value for the participants. In this category, participants drew images of items such as the school mascot, equations, flags, bar graphs, etc. These are not images of physical attributes, activities or hobbies; however, they may convey other significant aspects pertaining to how the participants perceive their identities. Figure 5 is an example of a value symbolic image

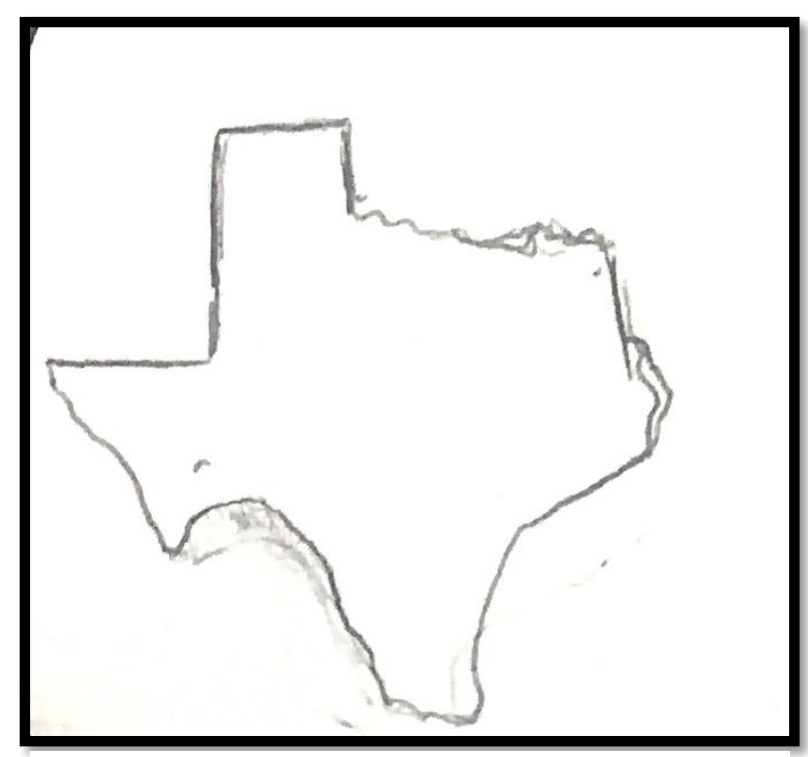

Figure 5. Value Symbolic Image 


\section{Discussion}

Touted as an exploratory method of inquiry and analysis, arts-informed research approaches exemplify the constructivist epistemology which proposes that there are multiple realities and ways of knowing [21]. In studies of identity, arts-informed approaches may offer an additional level of communicative flexibility when compared to other qualitatively driven approaches. More specifically, through this approach, participants can convey various aspects of their identities in manners that reflect their interests and level of artistic comfort.

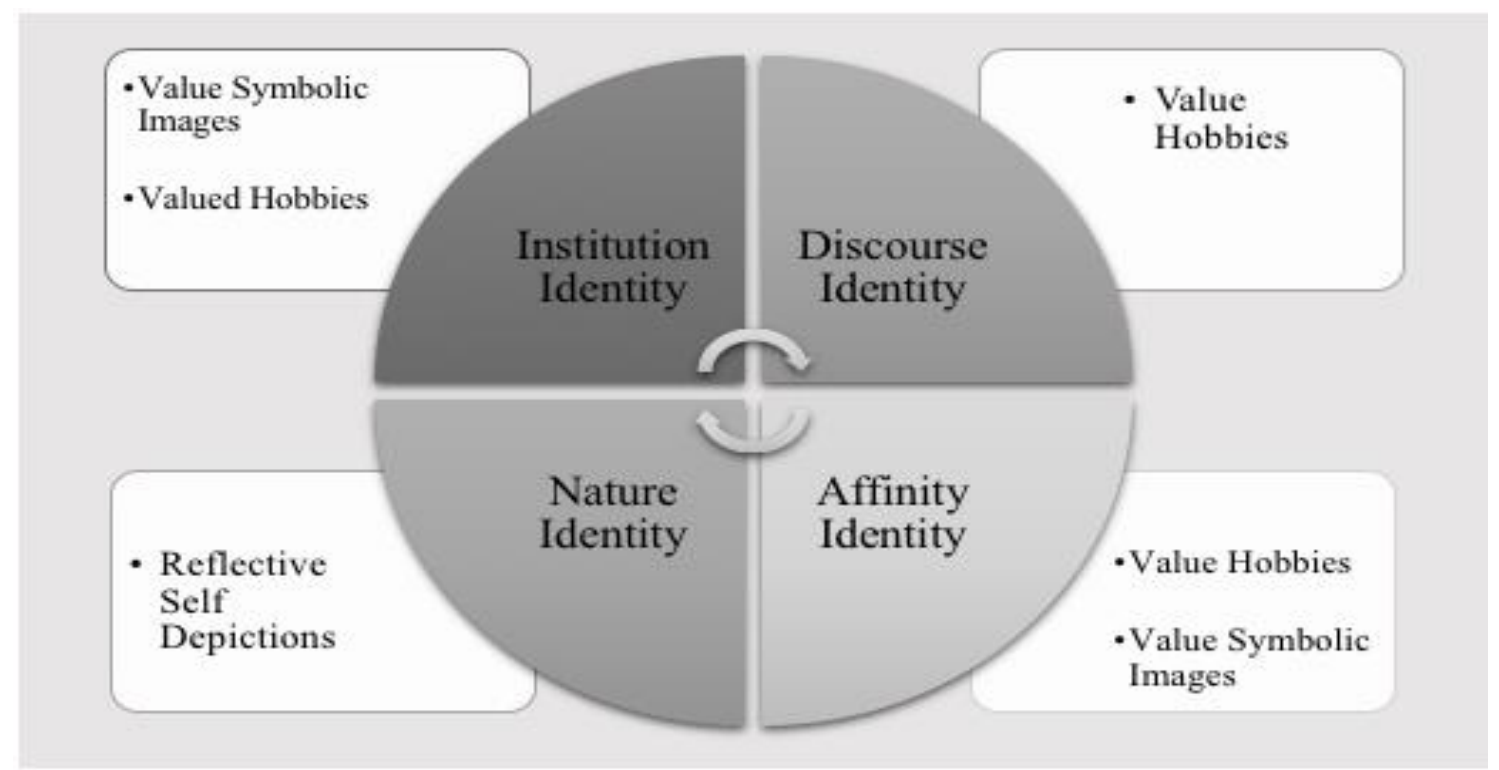

Figure 6. Aligning Emergent Categories with Identity Typologies

Confirming the identity typologies presented by Gee [4], the three major categories (valued hobbies, reflective self-depictions, value symbolic images) that emerged from this study illustrate components of nature-identity, institution identity, and affinity identity. More importantly, each of these categories aligns with one or more of these typologies. For instance, Gee describes Affinity Identity as those "shared in the practice of affinity groups" [5]. They go on to describe how individuals may have identities aligned with the affinity groups they have had experiences with. This description is in alignment with our codes for Value Hobbies and Value Symbolic Images. For example, a student who sketches the US flag may be understood as valuing the nation as part of their identity. We found codes primarily related to Value Hobbies and Value Symbolic Images.

Based on the alignment of our codes to Gee's identity typologies, students largely communicated aspects of the identities that related to the affinity experience and institutional identity. For example, we found more sketches which we coded as Value Hobbies (e.g., sketches to depict running, basketball, guitar, etc.) and Value Symbolic Images (e.g., sketches to depict the US national flag, institution mascot). Over these two typologies, participants demonstrated the greatest degree of intersection focusing their drawings on the hobbies that best inform their individual identities as well as the symbols that represent the institutions, disciplines, and metacognitive reflections. While most of these depictions did not explicitly connect to engineering, much of the discipline-specific symbolic drawings were images of mathematical 
symbols and computers. These particular symbols may be related to the educational components that inform students' major and career choices. Without longitudinal evidence, however, making inferences about student interest and declarations based on their identity maps is challenging; thus, the authors intend to study this potential relationship in future work.

Another interesting pattern to emerge from the analysis of the identity map was the near absence of depictions related to nature identity. While several participants drew images of themselves, these drawings lacked references to basic demographics such as race, ethnicity, and gender as well as other nature components of identity. This emergence suggests that participants connected more to external factors when communicating their identities, factors that are determined by the institutions of which they are a part.

Gee found that their four constructs were not separate from each other and that they inter-related in "complex and important ways." They also emphasize that the identity emergent from the kind of person one is at a given time and place, also changes, as expected, over the course of contexts, interactions and can be ambiguous or unstable. Thus, we acknowledge that the insights that the sketches reveal may indeed reflect partial, ambiguous, or transient self-reflections of identity of the students. However, these insights may still be valuable for those interested in understanding the incoming freshmen engineering cohorts, and their identity beliefs. For example, instructors of first-year programs, knowing the interests of students in their classroom, may provide engineering examples which can then help the student relate their affinity groups (e.g., guitar playing) to the broader engineering affinity groups (e.g., sound engineering, physics of sound waves, etc.). Specific to this research, the varied responses we received confirm the flexibility of expression offered through the arts-informed approach. Furthermore, the findings of this inquiry illuminate the potential of arts-informed research as another methodological avenue in which to confirm or refute theoretical frameworks of identity.

\section{Summary and Future Directions}

Engineering identity and its development have been extensively studied. In this paper, we present our findings from an exploratory research study analyzing first-year engineering student sketches of themselves to uncover facets of their individual identities. Our research study is driven by an arts-based approach which allows the students to express themselves beyond words using sketches, line figures, and the combination of words and sketches to depict themselves. We then used Gee's identity typologies to qualitatively code the sketches and found that most of the sketches aligned with affinity-identity and institution identity, and very few instances of discourse-identity and nature-identity. Thus, we observed that while several participants sketched themselves, their drawings did not refer demographic characteristics such as race, ethnicity or gender. Although on the surface, this may reveal that the students whose sketches were analyzed may not value gender, race or ethnicity as predominant parts of their identities, we are hesitant to draw conclusive results since these may also be a result of the limited opportunities that sketching may afford students to express nature identity. Thus, immediate future work for this research area would be to follow up the study by conducting one-on-one interviews with the students for them to explain or elaborate upon their sketches, and then tie those elaborations with written or verbal statements of their identity. 
Despite the limitations regarding what can be inferred from the dataset, and limitations for generalizability of the findings, this study contributes to existing work on engineering student identity. We have explored a unique research method to allow students to express their individual identities, and we believe that similar arts-based methodologies will benefit the field of engineering education by providing researchers with a unique perspective into participants' thought processes and beliefs.

\section{References}

[1] S. Song and A. M. Agogino, "Insights on designers' sketching activities in new product design teams," in ASME 2004 International Design Engineering Technical Conferences and Computers and Information in Engineering Conference, 2004, no. September, pp. 351-360.

[2] E. S. Ferguson, "Engineering and the Mind's Eye," in Engineering and the Mind's Eye, Cambridge: MIT Press, 1993, pp. 75-113.

[3] K. L. Tonso, "Engineering identity," Cambridge handbook of engineering education research, pp. 267-282, 2014.

[4] J. P. Gee, "Identity as an Analytic Lens for Research in Education," Review of Research in Education, vol. 25, pp. 99-125.

[5] N. R. Council, "Committee on the Guide to Recruiting, Advancing Women Scientists, Engineers in Academia, Committee on Women in Science, Engineering: To recruit and advance: women students and faculty in science and engineering," National Academies Press, Washington, DC, 2006.

[6] M. C. Paretti and L. D. McNair, "Analyzing the intersections of institutional and discourse identities in engineering work at the local level," Engineering Studies, vol. 4, no. 1, pp. 55-78, 2012.

[7] R. H. McKim, Experiences in Visual Thinking. Monterey: Brooks/Cole, 1972.

[8] E. Frankenberger, P. Badke-Schaub, and H. Birkhofer, Designers: the key to successful product development. Springer Science \& Business Media, 2012.

[9] G. Goldschmidt and M. Smolkov, "Variances in the impact of visual stimuli on design problem solving performance," Design Studies, vol. 27, no. 5, pp. 549-569, 2006.

[10] M. Schütze, P. Sachse, and A. Römer, "Support value of sketching in the design process," Research in Engineering Design, vol. 14, no. 2, pp. 89-97, 2003.

[11] R. Sennett, The craftsman. Yale University Press, 2008.

[12] C. Charyton and J. a. Merrill, "Assessing general creativity and creative engineering design in first year engineering students," Journal of Engineering Education, vol. 98, no. 2, pp. 145-156, 2009.

[13] R. Guay, "Purdue Spatial Visualization Test-Visualization of Views," Purdue Research Foundation, West Lafayette, IN, 1977.

[14] P. Leavy, Method meets art: Arts-based research practice. Guilford Publications, 2015.

[15] C. D. Edwards, "Examining Acculturation Strategies in Immigrant and Refugee Youth: A Mixed Methods Approach to Arts-Informed Research." Virginia Tech, 2017.

[16] NSF, “TABLE 5-1 . Bachelor's degrees awarded, by sex and field : $2004-14$, , 2016.

[17] D. S. Ozkan and D. Bairaktarova, "The Artistic Identities of First-Year Engineering Students," in ASEE Annual Conference \& Exposition, 2017.

[18] V. A. Anfara Jr, K. M. Brown, and T. L. Mangione, "Qualitative analysis on stage: 
Making the research process more public," Educational researcher, vol. 31, no. 7, pp. 2838, 2002.

[19] K. Charmaz and L. Belgrave, "Qualitative interviewing and grounded theory analysis," The SAGE handbook of interview research: The complexity of the craft, vol. 2, pp. 347$365,2012$.

[20] T. N. Ghezeljeh and A. Emami, "Grounded theory: Methodology and philosophical perspective," Nurse Researcher (through 2013), vol. 17, no. 1, p. 15, 2009.

[21] L. Butler-Kisber, Qualitative inquiry: Thematic, narrative and arts-informed perspectives. Sage Publications, 2010. 